\title{
Urinary Fibronectin Excretion in Streptozotocin-Diabetic Rats
}

\author{
Eleonore Jonas, Irmtrud Jäckle-Meyer, Borika Szukics and Hilmar Stolte')
}

Arbeitsbereich Experimentelle Nephrologie, Abteilung für Nephrologie, Zentrum für Innere Medizin und Dermatologie, Medizinische Hochschule Hannover, Hannover, Germany

\begin{abstract}
Summary: Previous investigations performed in human diabetics demonstrate an increase in their urinary fibronectin excretion which was already present in subjects without microalbuminuria and which was elevated prior to functional restrictions. The present study was performed to examine whether in an experimental model these data obtained in men can be confirmed using an animal experimental model, and to further study pathomechanisms of diabetic nephropathy in rats. Fibronectin levels in serum and urine, and renal functional properties such as creatinine clearance, urinary albumin and protein excretion were studied in rats rendered diabetic with streptozotocin and compared with values of control and insulin treated animals for 5 months. Diabetic animals demonstrated the same creatinine clearance, but slightly decreased albumin and total protein excretion rates compared to controls and insulin "treated", euglycaemic animals. Diabetic rats showed a significantly increased excretion following day 42 compared to controls and insulin "treated" group. Concerning serum fibronectin, there was no significant difference between control, diabetic and insulin "treated" animals. The urinary fragment pattern of fibronectin was analyzed qualitatively by immunoblotting pattern and consisted of two main bands $\left(M_{\mathrm{r}} 66000\right.$ and 45000$)$. These bands were not altered in controls, insulin "treated" and diabetic rats, independent of the stage of renal involvement in diabetes.

Present data provide evidence that fibronectin excretion is elevated in diabetic animals prior to functional restrictions, confirming results obtained in human diabetics. Therefore, determination of urinary fibronectin can serve as a more sensitive indicator for renal involvement in diabetes mellitus than microalbuminuria or changes in glomerular filtration rate. Urinary fibronectin excretion may therefore serve as an early marker for the renal involvement in diabetes before the onset of clinical symptoms.
\end{abstract}

\section{Introduction}

Microalbuminuria is currently the first sign that may indicate an incipient diabetic nephropathy. However, before microalbuminuria can be diagnosed, morphological alterations in the kidney, such as basement membrane thickening and mesangial expansion, occur $(2,5,6)$, which can not be determined by non-invasive methods. In the kidneys of diabetics in comparison to the kidneys of healthy volunteers, increased amounts of fibronectin, a major component of the mesangial matrix of the glomeruli (7), are found by immunochemistry $(8,9)$.

Recently, Jäckle-Meyer et al. (10) reported an increased urinary fibronectin excretion in diabetic humans that was already present in subjects without microalbuminuria and was elevated prior to functional restrictions. Following this investigation, the authors hypothesize that urinary fibronectin excretion probably reflects the mesangial expansion due to the accumulation of extracellular matrix

1) Supported by the Deutsche Forschungsgemeinschaft Sto71/6-1 and Sto $71 / 6-2$ and the Commission of the European Community in the framework of the programme STEP (Science and Technology of Environment Protection) proteins caused by increased glucose concentration in the tissue. Their observations raise the question whether the excretion of urinary fibronectin might be one possibility to examine early stages of diabetes induced kidney impairment with non-invasive methods.

The present investigation was designed to examine whether, in an experimental model, data obtained in diabetic humans can be confirmed in an animal model, and to further study the mechanisms leading to elevated fibronectin excretion in urine. Because of striking similarities with respect to early alterations of basement membrane metabolism in diabetic humans and in diabetic rats (11), rats were used as an animal model for studying basement membrane and mesangial cell metabolism in diabetes.

Additionally, the present study was performed to investigate whether an elevated urinary fibronectin excretion is accompanied by alterations of the pattern of the breakdown products of fibronectin found in urine.

\section{Materials and Methods}

Animals, sampling procedure and induction of diabetes

Eighteen male Wistar Kryptorch rats (Zentrales Tierlabor, Medizinische Hochschule Hannover, Germany), weighing $251 \pm 21 \mathrm{~g}$ 
at the beginning of the study, were divided at random into three groups with six animals per group. In two groups diabetes was induced by the administration of a single intravenous injection of streptozotocin $(50 \mathrm{mg} / \mathrm{kg}$ body weight in $0.1 \mathrm{~mol} / 1$ citrate buffer, pH 4.5; Sigma, St. Louis, Mo. USA). Starting one week after the induction of diabetes, one group of the diabetic animals received a daily subcutaneous injection of about 6 IE insulin (MC-Insulin Novo Lente, Novo Pharmaceuticals, Copenhagen, Denmark), the other group had no further treatment. The animals of the control group received only one injection of $0.1 \mathrm{~mol} / \mathrm{l}$ citrate buffer.

During the whole observation period, animals had free access to rat chow (Altromin. Lage, Germany) and water ad libitum. Urine samples were collected over a 12-hour night period in metabolic cages just before and $7,14,28,49,63,90,118$ and 147 days after the induction of diabetes and the injection of citrate buffer, respectively. Coinciding with the urine samples, blood samples were taken from the retro-orbital plexus. All samples were supplemented with $10 \mathrm{ml} / 1$ of $0.1 \mathrm{~mol} / \mathrm{l}$ phenyl-methyl-sulphonyl-fluoride to inhibit protease activities.

\section{Renal function measurements}

Endogenous creatinine clearance was determined by measuring serum and urine creatinine with an automated creatinine analyzer (Model R2, Beckman Instruments, GmbH, Munich, Germany). Glucose was measured enzymatically with a commercially available test kit (Boehringer, Mannheim, Germany). Total urinary protein was analyzed according to Bradford (13) and urinary albumin by rocket-immunoelectrophoresis (14).

\section{Determination of fibronectin}

Fibronectin in serum and urine was determined quantitatively by a sandwich-enzyme-linked-immunosorbent-assay (15). The anti-fibronectin antibodies were purchased from Dako AS (Copenhagen, Denmark) and purified plasma fibronectin from Sigma Chemicals (St. Louis, MO, USA). Alkaline phosphatase was conjugated to the antibodies as described by Avrameas (16). Serum samples were diluted 10000 fold and urine samples had to be neutralized with solid tris-hydroxymethyl-amino-methane.

Urinary fibronectin was analyzed qualitatively by protein blotting as described elsewhere in detail (17). Briefly, urinary proteins were separated electrophoretically using a linear $5-16 \%$ sodium dodecyl-sulphate-polyacrylamide gradient gel and transferred onto nitrocellulose by semidry-blotting (Sartoblot-II-S, Sartorius, Goettingen, Germany) in a discontinuous buffer system (18). Fibronectin was specifically detected by incubating the nitrocellulose successively with anti-fibronectin antibodies raised in rabbits and antirabbit-IgG antibodies coupled to alkaline phosphatase, both purchased from Dako AS (Copenhagen, Denmark). Fibronectin was stained by the alkaline phosphatase reaction as described by Blake et al. (19).

\section{Statistical analysis}

The results are expressed as medians and ranges. The data obtained within a group during the course of the experiments were analyzed by the Wilcoxon test for paired samples. The data of the three experimental groups were compared with the Mann-Whitney test for independent samples. The level of significance was defined as $\alpha<0.05$.

\section{Results}

\section{Glucose concentration}

The development of diabetes was evaluated by measuring the serum concentrations of glucose after the induction of diabetes and by comparing the values with those of controls and insulin treated animals. The serum glu- cose concentrations for the three groups of animals are shown in table 1. As demonstrated by significant increases in serum glucose concentrations, diabetes was fully established 21 days after streptozotocin injection and hyperglycaemia stayed evident for the rest of the study period. The hyperglycaemic group had a mean blood glucose concentration of $25.9-32.0 \mathrm{mmol} / \mathrm{l} 21$ days following streptozotocin injection, which was significantly elevated $(p<0.05)$ over controls and diabetic euglycaemics. Following injection of insulin the serum glucose concentration decreased to hypoglycaemic values of $2.2(1.7-5.5) \mathrm{mmol} / \mathrm{l}$ on day 77. Control animals did not show appreciable changes in serum glucose concentration during the study period. On day 21 and day 104, insulin treated animals showed marked hyperglycaemia in comparison to controls.

\section{Creatinine clearance}

The creatinine clearance for the three study groups of animals is summarized in table 2 . In general, creatinine clearance of diabetic rats was in the same range as creatinine clearance of control and insulin treated, euglycaemic animals. Median values ranged from 3.07 to 5.28

Tab. 1 Glucose in serum of diabetic rats, insulin treated rats and controls (mmol/li; medians and ranges)

\begin{tabular}{rlcc}
\hline Days & Controls & $\begin{array}{l}\text { Insulin treated } \\
\text { animals }\end{array}$ & Diabetic animals \\
\hline 0 & $7.0(3.9-9.7)$ & $7.7(5.8-8.3)$ & $7.0(6.7-7.6)$ \\
21 & $9.0(8.6-9.7)$ & $21.7(12.7-31.5)^{\mathrm{a}, \mathrm{b}}$ & $28.5(25.9-32.0)^{\mathrm{a}, \mathrm{b}}$ \\
28 & $7.3(5.9-8.0)$ & $8.6(4.6-18.9)^{\mathrm{c}}$ & $28.6 / 25.6-29.8)^{\mathrm{a}, \mathrm{b}}$ \\
42 & $7.6(6.3-7.9)$ & $4.3(3.6-17.5)^{\mathrm{c}}$ & $29.1(22.3-36.4)^{\mathrm{a}, \mathrm{b}}$ \\
63 & $6.7(5.6-8.7)$ & $4.4(2.0-15.7)^{\mathrm{c}}$ & $27.7(24.5-29.9)^{\mathrm{a} . \mathrm{b}}$ \\
77 & $7.2(5.9-7.3)$ & $2.2(1.7-5.5)$ & $23.5(19.9-25.0)^{\mathrm{a}, \mathrm{b}}$ \\
104 & $6.8(5.9-8.1)$ & $21.9(1.6 .9-23.0)$ & $31.9(30.7-39.2)^{\mathrm{a}, \mathrm{b}}$ \\
132 & $6.1(5.4-7.0)$ & $15.4(7.3-29.3)$ & $33.6(27.3-40.6)^{\mathrm{a}, \mathrm{b}}$ \\
161 & $6.9(5.7-8.0)$ & $8.4(7.8-24.6)$ & $28.3(24.1-30.5)^{\mathrm{a}, \mathrm{b}}$ \\
\hline
\end{tabular}

a significance vs. value at day 0 ;

b significance vs. controls;

c significance vs. diabetic animals.

Tab. 2 Creatinine clearance of diabetic rats, insulin treated rats and controls ( $\mathrm{ml} / \mathrm{min} \times \mathrm{kg}$; medians and ranges)

\begin{tabular}{rlll}
\hline Days & Controls & $\begin{array}{l}\text { Insulin treated } \\
\text { animals }\end{array}$ & Diabetic animals \\
\hline 0 & $6.06(4.98-6.81)$ & $6.68(5.75-7.21)^{\mathrm{c}}$ & $5.28(3.95-5.84)$ \\
21 & $5.05(4.25-6.76)$ & $7.12(6.95-8.73)^{\mathrm{b}, \mathrm{c}}$ & $4.16(1.52-4.98)$ \\
28 & $6.06(5.24-6.65)$ & $2.46(1.56-3.29)^{\mathrm{a}, \mathrm{b}}$ & $3.26(1.67-4.31)^{\mathrm{a}, \mathrm{b}}$ \\
42 & $4.43(3.77-4.91)$ & $7.86(6.13-8.13)^{\mathrm{b}, \mathrm{c}}$ & $4.51(2.46-5.36)$ \\
63 & $6.26(5.33-6.91)$ & $6.84(5.47-8.17)^{\mathrm{c}}$ & $3.92(2.96-5.68)^{\mathrm{b}}$ \\
77 & $5.74(4.47-7.21)$ & $6.30(5.85-6.99)$ & $3.28(1.52-5.83)$ \\
104 & $6.30(5.01-7.07)$ & $6.42(5.98-8.04)$ & $5.37(2.76-7.67)$ \\
132 & $6.98(6.12-8.97)$ & $3.40(3.11-4.16)$ & $5.57(2.67-7.47)$ \\
161 & $6.43(5.03-9.64)$ & $4.30(3.90-7.70)$ & $3.07(2.22-4.20)$ \\
\hline
\end{tabular}

a significance vs. value at day 0 ;

b significance vs. controls;

c significance vs. diabetic animals. 
$\mathrm{ml} / \mathrm{min} \times \mathrm{kg}$. However, at days 28,63 and 161 following steptozotocin injection, creatinine clearance of diabetic animals was significantly decreased compared to control animals. Creatinine clearance was constant during the rest of the study period. Insulin treated animals demonstrated a significantly increased value at days 21 and 42 , but decreased value at day 28 in comparison to control animals.

\section{Urinary protein excretion}

Total urinary protein excretion is shown in figure 1. There were significant decreases in urinary protein excretion, from 7.9 to $1.5 \mathrm{mg} / 12 \mathrm{~h}$, following the induction of diabetes in comparison to control animals. There was no significant difference between controls and euglycaemic animals.

\section{Urinary albumin excretion}

Urinary albumin excretion for the various groups is summarized in figure 2 . In all six diabetic rats, albumin excretion decreased statistically significantly during 42 days from 0.5 to $0.1 \mathrm{mg} / 12 \mathrm{~h}$ following streptozotocin injection in comparison to controls and insulin treated rats. In all six diabetic rats however, the relative contribution of albumin to total urinary protein increased (data not shown). Albumin excretion of euglycaemic, insulin treated animals did not increase significantly during the whole study period and was in the same range as values of control animals. At the end of the study period the average albumin excretion of control rats was 1.1 (0.92.1) $\mathrm{mg} / 12 \mathrm{~h}$ and did not differ significantly from the value in the beginning of the study period.
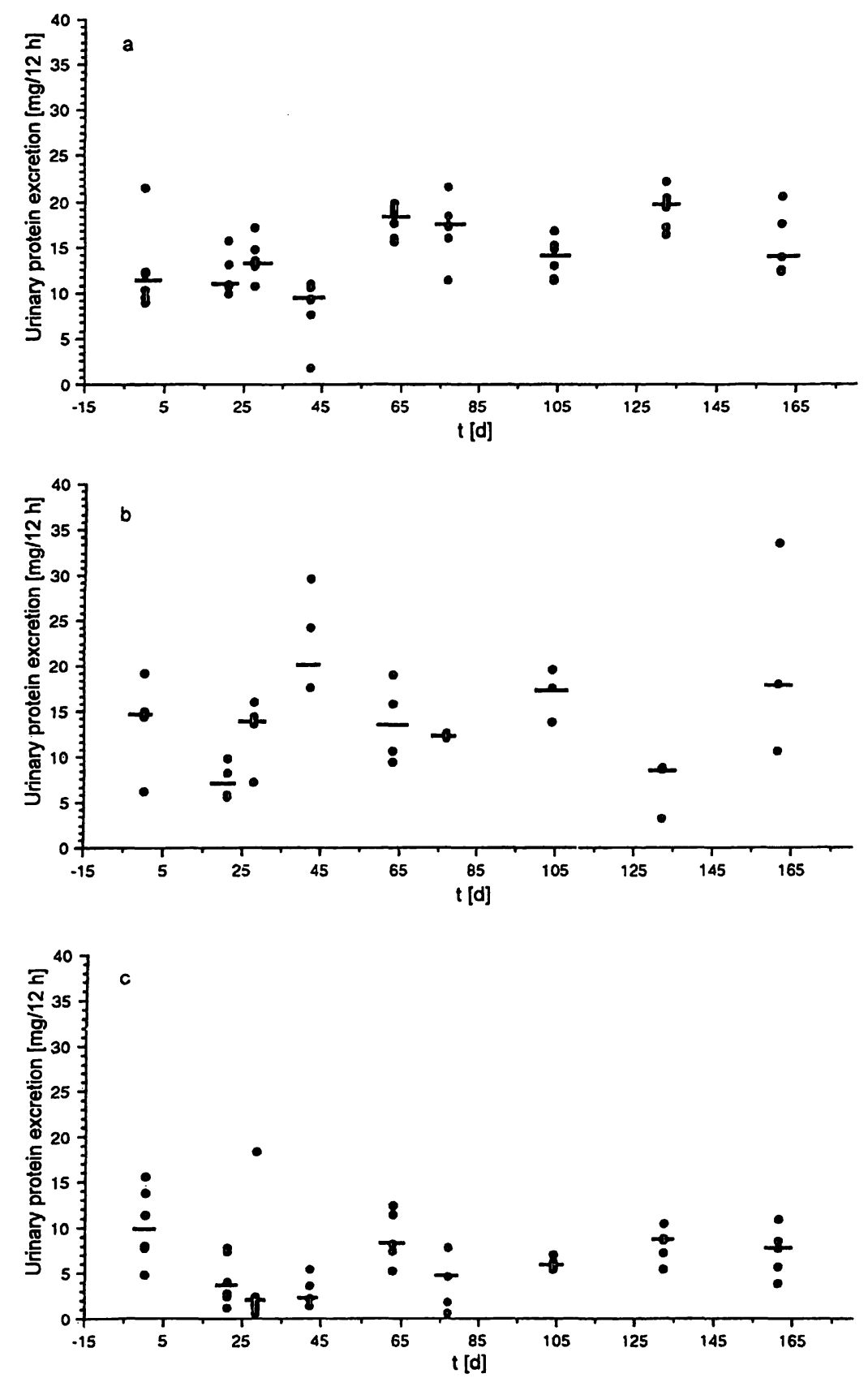

Fig. 1 Urinary protein excretion in diabetic animals (c), insulin treated animals (b) and controls (a). Horizontal bars represent the medians of the entire group. $\alpha<0.05$ 

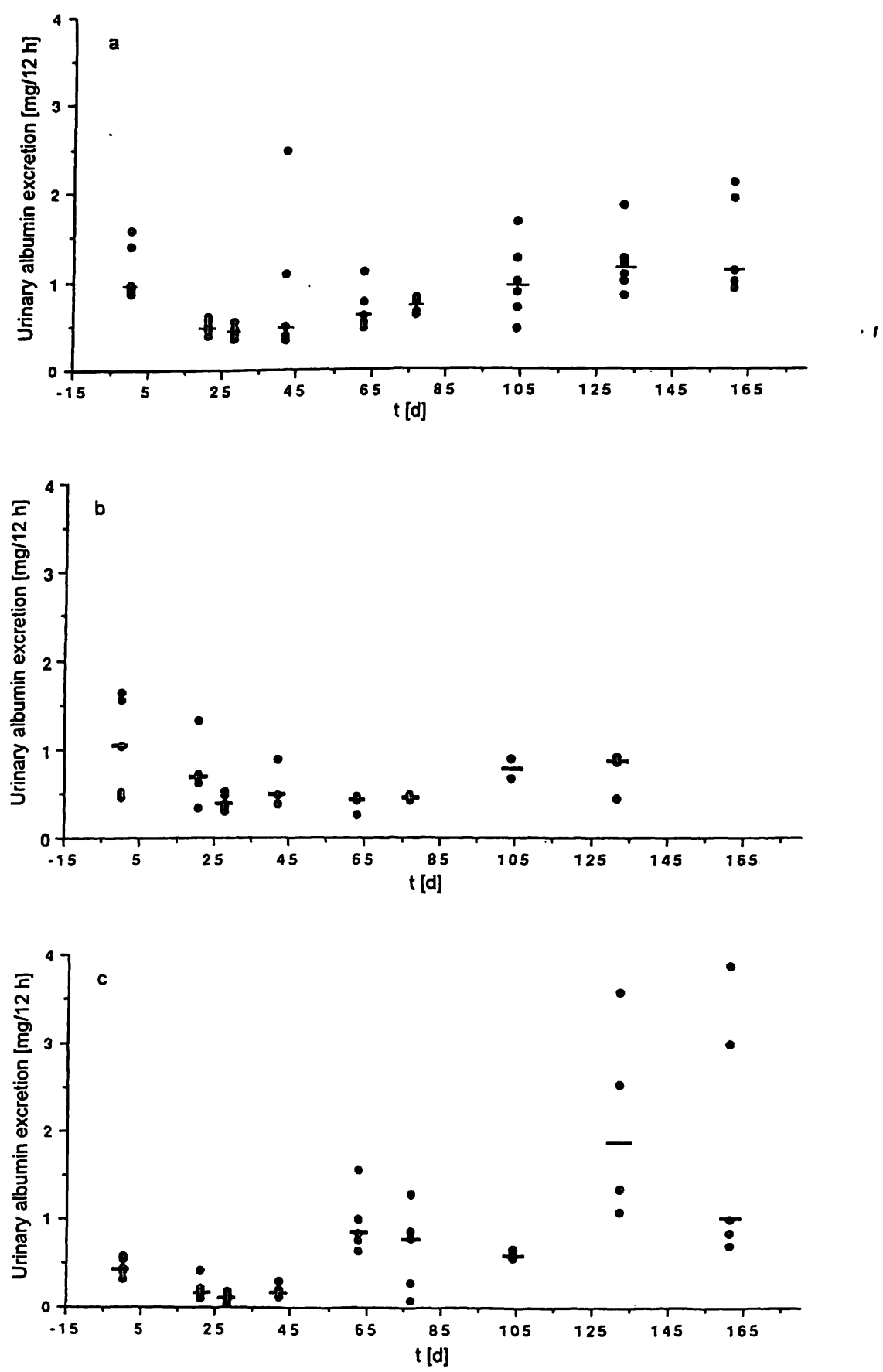

Fig. 2 Urinary albumin excretion in diabetic animals (c), insulin treated animals (b) and controls (a). Horizontal bars represent the medians of the entire group. $\alpha<0.05$

\section{Serum fibronectin}

Fibronectin levels were determined in serum of diabetic animals, insulin treated animals and control animals. These 3 groups showed no differences in serum fibronectin level concentrations during the whole observation period (tab. 3).

\section{Urinary fibronectin excretion}

The urinary excretion of fibronectin for all three groups is shown in figure 3 . The determination of urinary fibronectin showed an increased excretion in all diabetic rats following day 42 , from 117 to $703 \mathrm{ng} / 12 \mathrm{~h}$ compared to the control group and insulin treated group. The values differed markedly between different diabetic animals. Some diabetic rats excreted increased amounts of fibro- nectin much earlier. Fibronectin was elevated in urine of diabetic rats even when albumin excretion was not

Tab. 3 Fibronectin in serum of diabetic rats, insulin treated rats and controls (mg/; medians and ranges)

\begin{tabular}{rlll}
\hline Days & Controls & $\begin{array}{l}\text { Insulin treated } \\
\text { animals }\end{array}$ & Diabetic animals \\
\hline 0 & $220(131 / 300)$ & $163(102 / 275)$ & $200(153 / 414)$ \\
21 & $158(109 / 196)$ & $224(163 / 306)$ & $131(120 / 164)$ \\
28 & $184(112 / 124)$ & $305(169 / 408)$ & $153(112 / 203)$ \\
42 & $265(184 / 286)$ & $180(102 / 286)$ & $235(94 / 286)$ \\
63 & $384(307 / 583)$ & $352(214 / 418)$ & $361(296 / 424)$ \\
77 & $250(133 / 388)$ & $296(244 / 306)$ & $203(153 / 203)$ \\
104 & $316(143 / 327)$ & & $180(112 / 225)$ \\
132 & $122(112 / 288)$ & & $138(112 / 186)$ \\
161 & $362(245 / 581)$ & & $347(255 / 469)$ \\
\hline
\end{tabular}



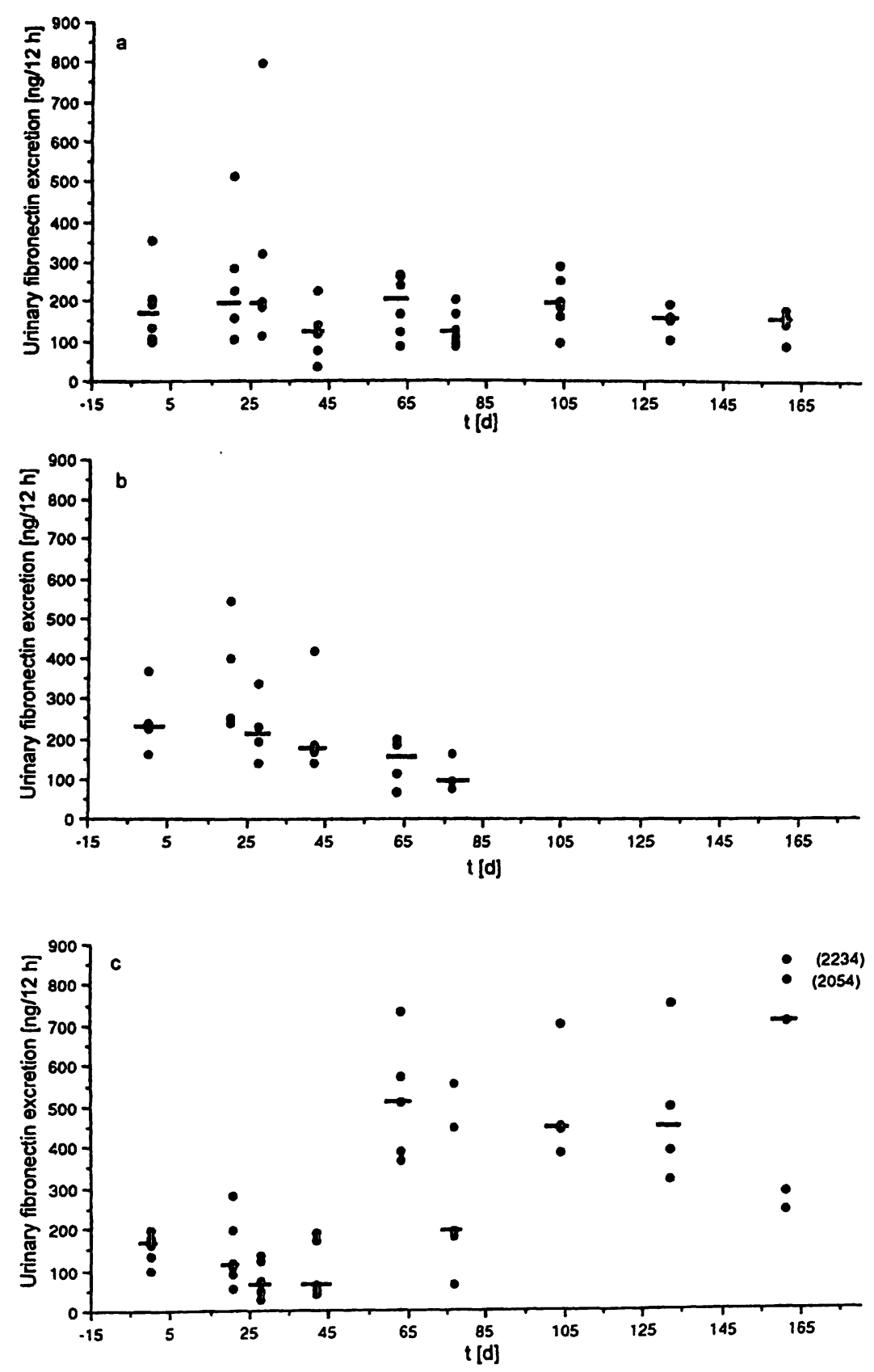

Fig. 3 Urinary excretion of fibronectin in diabetic animals (c), insulin treated animals (b) and controls (a). Horizontal bars represent the medians of the entire group. $\alpha<0.05$

elevated. In controls, no changes in fibronectin excretion could be observed. Values of medians ranged from 117 to $191 \mathrm{ng} / 12 \mathrm{~h}$. The excretion of fibronectin in insulin treated rats did not differ significantly from the excretion in control rats. In contrast to diabetic animals, fibronectin excretion of insulin treated animals did not increase.

\section{Qualitative evaluation}

A representative immunoblot is shown in figure 4. It was demonstrated that fibronectin was excreted in a distinct, recurrent fragment pattern consisting of two main protein bands with an apparent relative molecular mass of $M_{\mathrm{r}} 66000$ and 45000 . The urinary fragment pattern of fibronectin was similar in all 3 animal groups and did not alter during the whole study period, independent of the stage of renal involvement in diabetes.

\section{Discussion}

To search for significant pathogenetic mechanisms in the renal disease of insulin-deficient diabetes, research has recently been focused on early events. The present study was designed to compare pathomechanisms of nephropathy in humans with those in rats and to further study mechanisms leading to elevated fibronectin excretion in urine.

Because of striking similarities with respect to the alterations of basement membrane metabolism in diabetic humans and in diabetic rats (11), rats served as an exper- 


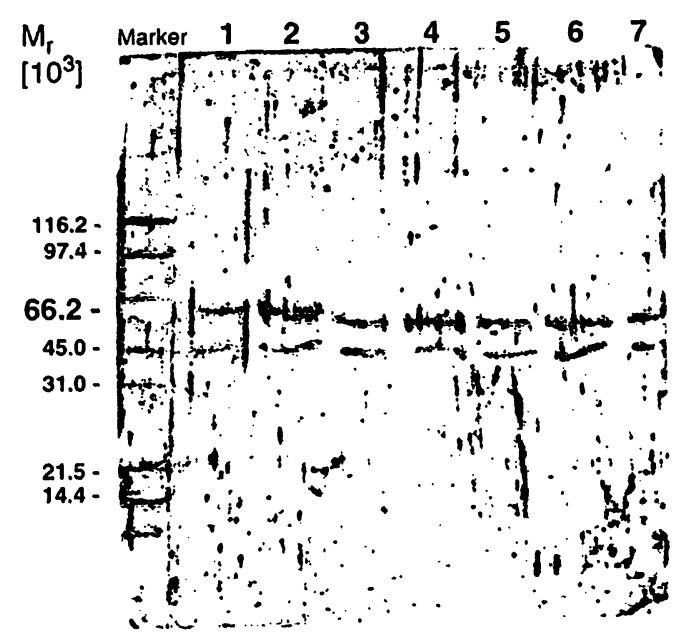

Fig. 4 Representative immunoblot of the urinary fragment pattern of fibronectin of control, diabetic and insulin treated animals. Two bands in the range of $M_{\mathrm{r}} 45000$ and 65000 were present in all samples.

lane 1: control rat at day 0

lane 2: control rat at day 63

lane 3: diabetic rat at day 63

lane 4: insulin treated rat at day 63

lane 5: control rat at day 161

lane 6: diabetic rat at day 161

lane 7: insulin treated rat at day 161

imental animal model. Most of the morphological alterations observed in untreated diabetic rats - especially early changes - are observed as well in humans (11). Rats, though, do not develop diabetic sclerosis, as described by Kimmelstiel (23).

Glucose concentration was measured to prove whether animals were diabetic and whether insulin treatment had effects. Steptozotocin-treated animals exhibited elevated blood glucose levels over the two other groups, the insulin treated animals and control animals demonstrating that diabetes was fully established 21 days after streptozotocin injection and was successful over the whole study period.

Diabetic animals had no increased creatinine clearance compared to the two other study groups. This observation suggests that an early stage of renal impairment could not be observed. Regarding total protein excretion, diabetic rats and insulin treated rats did not develop proteinuria during the first weeks of the study period. An explanation in the present study could be the diabetic acidosis leading to degrading of proteins. We could not confirm studies made by other authors $(25,26,27)$ who demonstrated that, just as in type I diabetic patients, diabetic rats show a higher rate of creatinine clearance and excretion of urinary protein. Treatment of the rats by insulin led to rapid normalization of the functional alterations (28). These authors state that the structural and functional alterations in rat kidneys detected immediately after induction of diabetes are very similar to those observed in patients during the first stage of diabetic nephropathy (11). These observations apply irrespective of the methods used for inducing diabetes (alloxan, streptozotocin) (11).

The extent of renal involvement in diabetic rats was specified by total protein excretion and by urinary albumin excretion, since microalbuminuria is currently the most sensitive marker in humans and predictive for the development of diabetic nephropathy (22). Control rats as well as insulin treated rats did not demonstrate an increased albumin excretion, indicating that the process of glomerular injury had not begun. Also urinary albumin excretion in diabetic rats suggests that an early stage of renal impairment could not be observed. In general, diabetic animals showed individual differences in albumin excretion. In some cases extremely increased levels of albumin excretion could be demonstrated.

This effect cannot be explained by aging alone, but also by a diabetes induced kidney impairment. Although microalbuminuria in diabetic rats has not been described yet, it can be concluded that rats are quite useful for studying early and intermediate stages of diabetic nephropathy because of similar morphological changes. Rats investigated in the present study show an early stage of nephropathy without striking functional changes.

In the present study, fibronectin concentration in serum was not increased in diabetic animals in comparison to insulin treated and control rats during the whole study period. Studies performed by other authors showed inconsistent results regarding human diabetics. LabatRobert et al. (29) found a decreased plasma fibronectin level in diabetics, whereas DeGiorgio et al. (30) reported increased levels in patients with retinopathy and microalbuminuria. Davis et al. (31) could not find any difference in serum fibronectin content in diabetic and nondiabetic persons. Regarding serum fibronectin levels in rats, only a few studies have been made by other authors. The increased concentration of serum fibronectin described in diabetic humans is probably not present in rats $(32,33)$.

There was a difference in urinary fibronectin excretion between euglycaemic and hyperglycaemic diabetic animals, despite the fact that these groups did not exhibit differences in renal function. Fibronectin was elevated in urine of diabetic rats even when albumin excretion was not elevated, whereas fibronectin excretion in insulin treated rats was not elevated during the whole study period and was not different from the fibronectin excretion in control rats. These results provide evidence that fibronectin excretion is elevated in diabetic animals prior to functional restrictions. Therefore, our data obtained in rats demonstrate that fibronectin can be modulated by insulin treatment and give evidence for renal involvement in diabetes mellitus. Because treatment with insulin prevented increase in fibronectin excretion, 
this indicates that urinary fibronectin level is a consequence of the diabetic state. According to the results in diabetic rats, the euglycaemia found in insulin treated rats has been shown to result in decreased fibronectin excretion. Studies of Jäckle-Meyer et al. (10) obtained in humans could be confirmed by studies in rats, demonstrating that increased urinary fibronectin excretion in diabetics was already present in subjects without microalbuminuria.

Furthermore, the reported effects in insulin treated animals can be explained by the hypothesis of some authors who have described changes in uracil ribonucleotide metabolism that can be prevented by insulin administration in the renal cortex of the streptozotocin-induced diabetic rat (34). In the present study, increased excretion of urinary fibronectin excretion could be demonstrated after induction of experimental diabetes and following increased serum glucose levels. A possible explanation comes from studies performed by Kreisberg et al. (35), who show that fibronectin is elevated in response to high glucose. Results presented by these authors by quantitative RT-PCR showed that high glucose resulted in a rapid, transient increase in c-fos mRNA followed by a sustained increase in c-jun and fibronectin mRNA in mesangial cell cultures.

Since the urinary excretion of fibronectin seems to be valuable in assessing the early involvement of the kidney in diabetes, the fibronectin excretion was studied not only quantitatively but also qualitatively by immu-

\section{References}

1. Osterby R. Morphometric studies of the peripheral glomerular basement membrane in early juvenile onset diabetes. Development of initial basement membrane thickening. Diabetologia 1972; 8:84-7.

2. Osterby R, Parving HH, Hommel E, Jorgensen HE, Lokkegaard $\mathrm{H}$. Glomerular structure and function in diabetic nephropathy. Early to advanced stage. Diabetes 1990; 39:1057-63.

3. Warren S, Le Compte PM, Legg MA. The pathology of diabetes. Philadelphia: Lee \& Febiger, 1966:231-46.

4. Sandahl CM, Frandsen M, Parving HH. Effect of intravenous glucose infusion on renal function in normal man and in insulin-dependent diabetes. Diabetologia 1981; 21:368-74.

5. Mauer SM, Michael AF, Fish AJ, Brown DM. Spontaneous immunoglobulin and complement deposition in glomeruli of diabetic rats. Lab Invest 1972; 27:488-94.

6. Schleicher E, Nerlich A, Gerbitz KD. Pathobiochemical aspects of diabetic nephropathy. Klin Wochenschr 1989; 66:873-82.

7. Dixon AJ, Burns J, Dunnill MS, Mc Gee J. Distribution of fibronectin in normal and diseased human kidneys. J Clin Pathol 1980; 30:1021-8.

8. Funabiki K. Immunohistochemical analysis of extracellular components on the glomerular sclerosis of extracellular components on the glomerular sclerosis in patients with glomerulonephritis and diabetic nephropathy. Nippon Jinzo Gakkai Shi 1989; 31 (1):111-20.

9. Oomura A, Nakamura T, Arakawa M, Ooshima A, Isemura M. Alterations in the extracellular matrix components in human glomerular diseases. Virchows Arch 1989 (A); 415:151-9. noblotting. The aim was to investigate whether the elevated urinary excretion of fibronectin is accompanied by alterations of the pattern of the breakdown products of fibronectin found in urine. The protein was excreted in a distinct fragment pattern of two main bands with an apparent relative molecular mass of $M_{\mathrm{r}} 66000$ and 45000 in the urine of control and of diabetic animals, independent of the stage of renal involvement in diabetes.

According to Gwinner et al. (17), urinary fibronectin fragments derive from the glomerulus under non-proteinuric conditions. Because none of the rats in the present study developed proteinuria, the unaltered and recurring fragment pattern is indicative that these fragments are products of a defined turnover of fibronectin in the kidney.

In summary, it was shown that urinary fibronectin excretion is elevated in diabetic rats prior to functional restrictions. It probably reflects the mesangial expansion due to the accumulation of extracellular matrix proteins, like fibronectin, caused by increased glucose levels in the tissue. With regard to these findings, urinary fibronectin excretion may serve as an early marker for the renal involvement in diabetes. This demonstrates the existence of a very early quantitative but not qualitative change in urinary fibronectin excreted in diabetic rats. Furthermore, it could be demonstrated in the present study that rats provide a useful animal model for further studying the underlying mechanisms leading to increased fibronectin excretion in diabetes mellitus.

10. Jäckle-Meyer I, Szukics B, Neubauer K, Metze V, Petzoldt R, Stolte H. Extracellular matrix proteins as early markers in diabetic nephropathy. Eur J Clin Chem Clin Biochem 1995; 33:211-19.

11. Hasslacher C. Development of diabetic nephropathy in the rat: morphological, functional, and pathophysiological aspects. Contr Nephrol 1988; 66:9-17.

12. Mauer SM, Steffes MW, Ellis EN, Sutherlands DER, Brown DM, Goetz FC. Structural-functional relationship in diabetic nephropathy. J Clin Invest 1984; 74:1143-55.

13. Bradford MM. A rapid and sensitive method for the quantitation of microgram quantities of protein utilizing the principle of protein-dye binding. Anal Biochem 1976; 72:248-54.

14. Laurell CB. Quantitative estimation of proteins by electrophoresis in agarose gel containing antibodies. Anal Biochem 1966; $15: 45-52$.

15. Engvall E. Fibronectin. In: Bergmeyer HU, editor. Methods of enzymatic analysis. Weinheim: VCH Weinheim, 1996:20111 .

16. Avrameas S. Coupling of enzymes to proteins with glutaraldehyde. Immunochemistry $1969 ; 6: 43$.

17. Gwinner W, Jäckle-Meyer I, Stolte H. Origin of urinary fibronectin. Lab Invest 1993; 69:250-5.

18. Bjerrum OJ, Heegaard NHH. Handbook of immunoblotting of proteins. Boca Raton: CRC press Inc., 1988:79-85.

19. Blake MS, Johnston KH, Russell-Jones GJ, Gotschlich EC. A rapid, sensitive method for detection of alkaline phosphataseconjugated anti-antibody on western blots. Anal Biochem 1984; 136:176-9. 
20. Hans-Henrik P, Mauer SM. Diabetic nephropathy: The Second World Conference on Diabetes Research, New Frontiers. The Juvenile Diabetes Foundation International 1988:28-33.

21. Knowles HC, Guest GM, Lampe J. The course of juvenile diabetics treated with measured diet. Diabetes 1975 ; 14:23973.

22. Mogensen CE. Microalbuminuria as a predictor of clinical diabetic nephropathy. Kidney Int 1987; 31:573-89.

23. Kimmelstiel P. Diabetic glomerulosclerosis and microangiopathy. Int Forum 1968; 16:44-67.

24. Petersen J, Ross J, Rabkin R. Effect of insulin therapy on established diabetic nephropathy in rats. Diabetes 1988; 37:134650.

25. Hostetter TH, Troy JL, Brenner BM. Glomerular hemodynamics in experimental diabetes mellitus. Kidney Int 1981; 19:410-5.

26. Michels LD, Davidman M, Keane WF. Determination of glomerular filtration and plasma flow in experimental diabetic rats. J Lab Med 1981; 198:869-85.

27. Weil R, Nowaza M, Koss M, Reemtsma K, McIntosh $R$. The kidney in streptozotozin diabetic rats. Arch Pathol Lab Med $1976 ; 100: 37-49$.

28. Jensen PK, Christiansen JS, Steven K, Parving HH. Strict metabolic control and renal function in the streptozotocin diabetic rat. Kidney Int 1987; 31:47-51.

29. Labat-Robert J, Leutenegger M, Lopis G, Ricard Y, Derouette JC. Plasma and tissue fibronectin in diabetes. Clin Physiol Biochem $1984 ; 2: 39-48$.
30. DeGiorgio LA, Bartolomei G, Gironi A, Caselli P, Seghieri G. Increased plasma fibronectin concentration in diabetic patients with albuminuria. Diabetes Care 1988; 11:527-30.

31. Davis TME, Moore JC, Turner RC. Plasma fibronectin, factor VIII-related antigen and fibrinogen concentrations, and diabetic retinopathy. Diabete \& Metabolisme 1985; 11:147-51.

32. Inoguchi $T$, Umeda $F$, Watanabe $J$, Wasada $T$, Ibayashi $H$. Plasma fibronectin and platelet aggregation in diabetes mellitus. Diabetes Res Clin Pract 1986; 2:69-73.

33. Solerte SB, Piovella F, Viola C, Schianca GC, Gamba G, Fioravanti $M$, Ferrari E. Plasma fibronectin, von Willebrand factor antigen, and blood rheology. Association with diabetic microvascular disease. Acta Diabetol Lat $1985 ; 22: 239-46$.

34. Cortes P, Levin NW, Dumler F, Rubenstein AH, Verghese CP, Venkatachalam KK. Uridine triphosphate and RNA synthesis during diabetes-induced renal growth. Am J Physiol 1980; 238:E349-57.

35. Kreisberg J, Radnik RA, Ayo SH, Garoni J, Saikumar G. High glucose elevates c-fos and c-jun transcripts and proteins in mesangial cell cultures. Kidney International 1994; 46:10512.

Received August 25, 1995/April 10, 1996

Corresponding author: E. Jonas, Medical School Hannover, Department of Internal Medicine and Dermatology, Division of Nephrology (Experimental Nephrology), Konstanty-GutschowStraße 8, D-30625 Hannover, Germany 